\title{
Propuestas de métodos de enseñanza de disciplinas que integran el eje de formación fundamental de acuerdo a las directrices curriculares de los programas de derecho en Brasil
}

\section{Teaching methodologies proposals of formative disciplines in the curricular guidelines of Law School Courses in Brazil}

Abili Lázaro Castro de Lima ${ }^{1}$

Resumo: O artigo tem por objetivo, primeiramente, demonstrar a importância e a necessidade dos conteúdos de Antropologia, Ciência Política, Economia, Ética, Filosofia, História, Psicologia e Sociologia no contexto dos Cursos de Direito no Brasil, os quais encontram-se inseridos no eixo de formação fundamental para atender a formação geral, humanística, crítica e reflexiva dos estudantes, consoante as diretrizes curriculares, introduzidas pela Resolução CNE n º 9/2004 do Ministério da Educação do Brasil. Em segundo lugar, transcorridos dez anos, fazer um levantamento dos desafios didáticos dos professores para atingir os objetivos das diretrizes curriculares, em especial considerando a tradição de um ensino jurídico baseado no comentário de artigos de leis ou de códigos. Em terceiro lugar, o artigo pretende apresentar propostas de metodologia de ensino, sobretudo na contextualização e a problematização do ensino teórico das referidas disciplinas que desenvolvem os conteúdos do eixo de formação fundamental com situações concretas do cotidiano, abordando algumas das metodologias de ensino empregadas, bem como das avaliações.

Palabras claves: Metodologías de enseñanza, disciplinas formativas, educación jurídica en Brasil

\begin{abstract}
Firstly, the paper aims to demonstrate the relevance and usefulness of the knowledge of Anthropology, Political Science, Economics, Ethics, Philosophy, History, Psychology and Sociology in Law School Courses in Brazil. This wide range of knowledge form part of the formative process in order to fulfill with the curricular guidelines introduced by the Resolution CNE $n^{\circ}$. 9/2004 of the Ministry of Education of Brazil; that is, to ensure the general, humanistic, critical and reflexive feature of legal education. The second aim pursued is focused on analyzing the educational challenges faced by members of law department in order to fulfill with curricular guidelines after ten years working. This effort represents an important work as it focuses on a tradition of a legal education model based on the commentary of legislation and its codes. Thirdly, the article aims to contextualize and challenge the theoretical teaching of the formative disciplines by presenting proposals of teaching methodologies and a evaluation focused on actual daily-life situations.
\end{abstract}

Keywords: Teaching methodologies, formative disciplines, legal education in Brazil

\footnotetext{
1 Professor Adjunto do Curso de Direito e do PPGD da Universidade Federal do Paraná das disciplinas Sociologia do Direito, Direito e Sociedade e Prática de Docência em Direito. Membro da Sociedade Brasileira de Sociologia.
} 


\section{A tradição dogmática do ensino jurídico brasileiro}

Antes de ingressarmos na apreciação modelos de ensino jurídico decorrente da implementação das diretrizes curriculares dos Cursos de Direito no Brasil, procederemos a uma análise dos modelos de ensino jurídico que as antecederam. ${ }^{2}$

Eliane Botelho Junqueira realiza um significativo estudo ${ }^{3}$ acerca dos modelos dos cursos jurídicos no Brasil, identificando o modelo do bacharel humanista e do profissional tecnicista: "O primeiro modelo nasce com o surgimento dos cursos de ciências jurídicas e sociais, pela lei de 11/08/1827, em Olinda e São Paulo. Os cursos tinham por objetivo proporcionar uma formação humanista e generalista aos bacharéis de direito, voltada a capacitá-los para o desempenho das atividades político-administrativas em substituição à burocracia portuguesa, visando a construção do Estado nacional, cuja independência havia sido recentemente conquistada". ${ }^{4}$

Jayme Paviani e José C. Pozenato resgatam o papel dos cursos jurídicos para o atendimento das necessidades sociais do Brasil Império, bem como de seu papel embrionário do surgimento das universidades. ${ }^{5}$

O modelo do profissional tecnicista nasce com a Reforma Universitária (Lei ${ }^{\circ}{ }^{\circ}$. 5.540/68) e se concretiza na reforma curricular dos Cursos de Direito (Resoluções n ${ }^{\circ} .03 / 72$ e 15/73). ${ }^{6}$

\footnotetext{
${ }^{2} \mathrm{O}$ desenvolvimento desta análise, obviamente, sem a pretensão de ser exaustiva, adequa-se às limitações da extensão do artigo, objetivando apenas e tão somente situar o leitor visando sua contextualização. Para atingir tal propósito, os três primeiros itens serão apresentados com base no artigo de nossa autoria "A função e a importância das disciplinas propedêuticas na estrutura curricular dos Cursos de Direito no Brasil”, 2006

${ }_{3}^{3}$ JUNQUEIRA, Eliane Botelho. A Sociologia Jurídica no Brasil: introdução ao debate atual, Lumen Juris, 1993 , 205 p.

${ }^{4}$ JUNQUEIRA, Eliane Botelho. Ibíd. p. 16-22.

${ }^{5}$ PAVIANI, Jayme e POZENATO, José C. A Universidade em debate, EDUCS, Caxias do Sul, 1980, p. 66: "No lugar da Universidade, seguiu-se no Brasil o modelo francês, de inspiração napoleônica, de criar escolas profissionais autônomas, para a formação de profissionais liberais: médicos, engenheiros e advogados. Esse modelo corresponde às necessidades da ordem social vigente, no sentido de reforçá-la. A Universidade, nesse contexto, teria uma função "desestabilizadora”, papel, aliás, desempenhado em parte pelas Faculdades de Direito, onde se desenvolveu a ideologia republicana. No período imperial, essas faculdades foram uma espécie de embrião de Universidade".

6 PAVIANI, Jayme e POZENATO, José C. Ibíd. p. 73-74: "As razões da implementação da Reforma Universitária foram assim definidas por Paviani e Pozenato: O principal motivo que levou à Reforma Universitária brasileira foi a tomada de consciência de que não havia Universidades no país e sim apenas instituições de ensino superior, agências de formação de profissionais liberais. A atividade de formação profissional, que deveria ser decorrência da atividade universitária, era na realidade sua meta exclusiva. Em conseqüência, a Universidade brasileira não era um centro de ciência e de cultura e também não correspondia às funções que deveria exercer na sociedade. [...] Um motivo mais imediato, e de maior força, foi a nova situação criada no país com o surto desenvolvimentista deflagrado pelo Governo de Juscelino Kubitscheck. O desenvolvimento mostrou a necessidade de uma diversificação maior de habilitações profissionais, além das tradicionais profissões liberais; passou a exigir a participação da Universidade na elaboração de novos conhecimentos, científicos e tecnológicos; e, sobretudo, provocou um crescimento explosivo da demanda pela formação universitária, até então buscada somente pelas elites sociais. Diante de todas essas novas exigências, constatou-se que a Universidade brasileira se encontrava despreparada, obsoleta, elitista, bacharelesca, em suma, afastada da missão cultural e científica que dela passava agora a esperar a sociedade (impunha-se, agora, com clareza, à consciência nacional, a necessidade de uma reforma universitária)".
} 
Os objetivos da Reforma Universitária foram: “a) modernização administrativa; b) renovação do conceito de ensino superior; c) integração da Universidade com o desenvolvimento da sociedade e d) redefinição do papel do Estado com relação à Universidade". ${ }^{7}$ Neste contexto, o modelo do ensino jurídico humanista entrou em crise ${ }^{8}$, uma vez que se encontrava divorciado dos objetivos da Reforma Universitária. ${ }^{9}$

$\mathrm{Na}$ esteira destas constatações, Paviani e Pozenato reforçam os efeitos negativos da formação profissionalizante em detrimento da formação humanística, reflexiva e crítica, sob os auspícios da Reforma Universitária de 1968. ${ }^{10}$

\footnotetext{
7 PAVIANI, Jayme e POZENATO, José C. Ibíd, p. 74-75.
}

8 JUNQUEIRA, Eliane Botelho. Ibíd, p. 22-23: "Na década de sessenta, o CEPED - Centro de Estudos e Pesquisas no Ensino do Direito desenvolveu estudos questionando o bacharelismo, consoante leciona Eliane Botelho Junqueira: O CEPED, que funcionou durante o período de 1967-1972, representou a tentativa de alguns professores de direito, sob a orientação de David Trubek, então Consultor Jurídico da United States for Internacional Development (USAID), de atualizar a formação do profissional de direito, tendo em vista as novas demandas do mercado empresarial brasileiro. [...] A este projeto de formação de juristas técnicos aptos a atenderem às necessidades derivadas do processo de desenvolvimento, somou-se a reformulação dos Cursos de Direito em 1972, na esteira da reforma universitária implantada em 1968".

${ }^{9}$ FARIA, José Eduardo e CAMPILONGO, CELSO FERNANDES. A Sociologia Jurídica no Brasil, 1991, p. 10-11: "As consequiências negativas do modelo do profissional tecnicista foram evidenciadas por José Eduardo Faria e Celso Fernandes Campilongo, ao analisarem a Reforma Universitária de 1968: [...], na lógica dos autores dessa reforma, às instituições universitárias caberia um papel eminentemente pragmático e utilitarista: ou seja, elas deveriam concentrar sua atenção na formação de quadros técnicos e gerenciais necessários à implementação do tipo de desenvolvimento econômico então vigente. Aos idealizadores dessa reforma apenas interessava, em nome dos objetivos "maiores" do regime burocráticomilitar pós-64, substituir o conceito "humanista" de formação cultural por uma progressiva racionalização e especialização do ensino superior, sob os requisitos da eficácia econômica e do avanço tecnológico. Precedida por um espúrio processo de afastamento das lideranças políticas e intelectuais, tal reforma acabou sendo manipulada pelos setores mais conservadores do establisment acadêmico. Estes setores, agindo em consonância com os interesses do regime, procuram integrar as ciências básicas a uma educação exclusivamente profissionalizante, valendo-se dessa estratégia mais como instrumento de controle político-ideológico da vida acadêmica do que propriamente de renovação do ensino e da pesquisa. A educação a nível universitário converteu-se, então, numa banal e descompromissada atividade de informações genéricas e/ou profissionalizantes - com os alunos sem saber ao certo o que fazer diante de um conhecimento transmitido de maneira desarticulada e pouco sistemática, sem rigor metodológico, sem reflexão crítica e sem estímulo às investigações originais. A ênfase à 'rentabilidade' educacional anulou por completo a função formativa da Universidade brasileira, mediante uma crescente marginalização das atividades criativas e críticas. Como decorrência, as estruturas universitárias se verticalizaram, em detrimento da autonomia acadêmica e da flexibilidade horizontal de projetos interdisciplinares, ao mesmo tempo em que os corpos docentes se dispersaram entre departamentos estanques e fechados em sua própria rotina burocrática. Ao voltar-se somente à produção de grandes contingentes de diplomados, dos quais a maioria absoluta destacava-se pela discutível qualidade de sua formação teórica e técnica, a Universidade brasileira progressivamente deixou-se transformar em simples agência cartorial transmissora de idéias pré-concebidas, incapaz de oferecer ao aluno respostas satisfatórias ao entendimento do meio ambiente e de preparação em termos de qualificação profissional. Esse processo de abastardamento do ensino superior tornou-se, no decorrer do regime pós-64, cada vez mais problemático, disfuncional e desagregador. [...].

${ }_{10}$ PAVIANI, Jayme e POZENATO, José C. Ibíd, p. 104: [...] Numa perspectiva mais ampla, porém, constata-se que a Universidade brasileira apenas diversificou e multiplicou as carreiras oferecidas - embora não tanto quanto o necessário, diga-se de passagem - mas permaneceu basicamente voltada para a formação profissional. A aparente modernização de fato foi a conservação da idéia de Universidade como mera agência de ensino. Some-se a isso que, como as novas profissões criadas visam o desempenho de funções técnicas, a formação humana tende a ocupar sempre menos lugar na educação superior brasileira. Essa formação é no entanto absolutamente necessária para que o profissional se torne capaz de colocar a técnica a serviço dos homens, sem risco de usá-la contra os homens. Numa Universidade tecnológica, não cabe o 


\section{As propostas de superação do modelo dogmático-tecnicista na formação dos Bacharéis em Direito}

Após verificarmos as consequências nocivas causadas pela concepção profissionalizante e tecnicista implementada pela Reforma Universitária de 1968, é importante discorremos sobre a nova concepção de ensino jurídico implementada pela Lei de Diretrizes e Bases da Educação (LDB) e pelas diretrizes curriculares dos Cursos de Direito definidas pelo Ministério da Educação a partir de 1994, a qual colocou a última pá de cal sobre o modelo do profissional tecnicista. ${ }^{11}$

O advento da LDB em 1994 inaugurou um novo panorama no ensino no Brasil, ao fortalecer a descentralização administrativa e acadêmica, possibilitando uma flexibilização curricular em contrapartida aos currículos mínimos herdados da reforma curricular dos cursos jurídicos ocorrida nos anos setenta. $\mathrm{O}$ ensino superior doravante terá por finalidade a formação do pensamento reflexivo e a formação de profissionais, conforme se depreende dos incisos I e II, do art. 43, da LDB. ${ }^{12}$

Sob a inspiração da LDB, o Ministério da Educação editou a Portaria $\mathrm{n}^{\circ} .1 .886 / 94$ que inseriu a flexibilização curricular no contexto dos Cursos de Direito, por meio das disciplinas optativas, áreas de habilitação e atividades complementares. Sem descurar das disciplinas profissionalizantes, enfatizou também o ensino reflexivo ao estabelecer a obrigatoriedade dos currículos contemplarem matérias fundamentais, tais como Filosofia (geral e jurídica); Ética (geral e profissional), Sociologia (geral e jurídica), Economia e Ciência Política (com Teoria do Estado). Acerca da interdisciplinariedade prevê que "as demais matérias e novos direitos serão incluídos nas disciplinas em que se desdobrar o currículo pleno de cada curso, de acordo com as peculiaridades e com observância de interdisciplinariedade" (art. $6^{\circ}$., parágrafo único). ${ }^{13}$

pensamento crítico e portanto a reflexão globalizante sobre o homem e a sociedade. Pensamento e reflexão tão vitais para o desenvolvimento como a própria tecnologia".

${ }^{11}$ Para a compreensão mais profunda do panorama do ensino do Direito no Brasil na contemporaneidade, indicamos a leitura do livro MACHADO, Antonio Alberto. "Capitulo 2". Ensino jurídico e mudança social, 2a. ed., Atlas, São Paulo, 2009, p. 33-65.

${ }^{12}$ Art. 43. A educação superior tem por finalidade: I - estimular a criação cultural e o desenvolvimento do espírito científico e pensamento reflexivo; II - formar diplomados nas diferentes áreas do conhecimento, aptos para a inserção em setores profissionais e para a participação no desenvolvimento da sociedade brasileira, e colaborar na sua formação contínua;"

${ }^{13}$ No que concerne à importância das disciplinas fundamentais e sua articulação com a interdisciplinariedade, são precípuos os ensinamentos de Paulo Luiz Neto Lôbo, em O novo conteúdo mínimo dos cursos jurídico, 1996, p. 10-11: A interdisciplinariedade, na dimensão externa ao saber dogmático jurídico, enlaça-se com matérias que contribuem para a formação do profissional de Direito, notadamente estimuladoras da reflexão crítica e da atuação político-institucional, que a sociedade cada vez mais dele reclama. Assim, a interessante abertura para as Ciências Sociais, Humanas, Políticas, para a Filosofia, incluindo as perspectivas lógica e ética, para a Psicologia, para a Informática, para a Ciência da Linguagem. [...] [...] O conteúdo mínimo é assim divido em três partes: a) a parte fundamental e reflexivo-crítica; b) a parte profissionalizante ou técnica-jurídica; c) a parte prática. Sempre sustentei, em trabalhos anteriores, que a formação jurídica assenta-se neste tripé. O curso jurídico, para bem desempenhar suas finalidades, deve atingir, de modo interindependente, a tríplice função de: a) formação fundamental e sócio-política, que forneça ao aluno uma sólida base humanística e de capacitação crítica; b) formação técnico-jurídica, que o capacite ao exercício competente de sua profissão reconhecendo que as disciplinas dogmáticas admitem espaço à reflexão crítica; c) formação prática, oferecendo-lhes os meios para aplicar os 
As novas diretrizes curriculares dos Cursos de Direito, instituídas pela Resolução n ${ }^{\circ} .9$ de 24 de setembro de 2004, do Conselho Nacional de Educação, prevêem no seu art. $4^{\circ}$., inciso VI, a necessidade, dentre outras, que o Curso de Direito possibilite a formação profissional despertando "a utilização do raciocínio jurídico, de argumentação, de persuasão e de reflexão crítica", devendo o curso, para tanto, contemplar tanto no seu Projeto Pedagógico quanto na sua estrutura curricular, conteúdos e atividades que atendam a três eixos de formação: 1) fundamental; 2) profissional e 3) prática $\left(\operatorname{art.} 5^{\circ}\right.$.).

No que pertine ao eixo de formação fundamental, as novas diretrizes curriculares ampliam o leque de conteúdos essenciais: Antropologia, Ciência Política, Economia, Ética, Filosofia, História, Psicologia e Sociologia. ${ }^{14} \mathrm{O}$ novo modelo de ensino jurídico que combina a formação geral, humanística, crítica e reflexiva com a formação profissionalizante e prática é expressamente previsto no art. $3^{\circ} .{ }^{15}$

\section{A importância e a necessidade das disciplinas do eixo de formação fundamental na estrutura curricular dos Cursos de Direito no Brasil}

Em que pese a obrigatoriedade do desenvolvimento dos conteúdos contidos no eixo de formação fundamental, com base nas diretrizes curriculares, há críticos que argumentam que os Cursos de Direito devem estar voltados tão somente à formação profissional (especialmente à formação de advogados), bem como devem prioritariamente capacitar os estudantes para serem aprovados nos exames para ingresso na Ordem dos Advogados do Brasil (OAB).

Alegam ainda que a carga horária dedicada aos conteúdos do eixo de formação fundamental que possibilitam a formação geral, humanística, reflexiva e crítica constitui um entrave para um maior aprofundamento do ensino das disciplinas profissionalizantes, obstando um melhor desempenho dos bacharéis no exercício da advocacia, no exame da OAB e nas demais carreiras jurídicas. Propõem que o ensino do Curso de Direito enfatize uma especialização nas disciplinas profissionalizantes.

conhecimentos obtidos. A matéria Filosofia (geral e jurídica), que pode estar desdobrada em mais de uma disciplina, deve incluir no conteúdo programático o estudo da ética geral e da ética profissional. Há espaço para inclusão do inquietante tema da bioética, que cada vez mais convida à meditação dos juristas. A obrigatoriedade da Sociologia jurídica rende homenagem à luta histórica de grandes sociólogos do Direito, no Brasil, como Cláudio Souto que, em suas obras sempre reclamou a imprescindibilidade desses estudos para a formação do profissional do Direito, abrindo-lhes horizontes para além da dogmática jurídica”. Com a Ciência Política pretende-se ir mais longe que o estudo clássico da teoria do Estado, embora esta continue. Interessa ao estudante de Direito que amplie sua compreensão aos fenômenos e estruturas políticas, à teoria do poder (e não apenas do poder político formal), à deontologia política. [...]”.

14 Acerca da importância e necessidade das disciplinas constantes no eixo de formação fundamental, bem como da Sociologia e Sociologia do Direito, vide nosso artigo "A função e a importância das disciplinas propedêuticas na estrutura curricular dos Cursos de Direito no Brasil", 2006, p. 77-85.

15 O curso de graduação em Direito deverá assegurar, no perfil do graduando, sólida formação geral, humanística e axiológica, capacidade de análise, domínio de conceitos e da terminologia jurídica, adequada argumentação, interpretação e valorização dos fenômenos jurídicos e sociais, aliada a uma postura reflexiva e de visão crítica que fomente a capacidade e a aptidão para a aprendizagem autônoma e dinâmica, indispensável ao exercício da Ciência do Direito, da prestação da justiça e do desenvolvimento da cidadania. 
Entendemos que tal proposta pretende ressuscitar o obsoleto modelo de ensino tecnicista que priorizava a formação profissionalizante, cujos efeitos nocivos já tivemos oportunidade de analisar.

Em que pese tal modelo estar superado, é importante trazermos algumas contribuições para o debate, uma vez que os defensores do seu resgate colocam em perigo as conquistas históricas do novo modelo representa.

Vamos analisar primeiramente a ênfase à especialização, ou seja, o argumento que o Curso de Direito deve prioritariamente formar advogados. Obviamente, um Curso de Direito tem por missão capacitar seus alunos para o exercício profissional. Todavia, o Curso de Direito não pode restringir sua formação à advocacia, uma vez que há, por óbvio, outras profissões jurídicas cuja vocação os alunos almejam exercer, as quais o Curso de Direito também deve possibilitar a formação.

Cláudio de Moura e Castro produziu um artigo bastante importante acerca da compreensão da especialização na atualidade, cujas lições são significativas para elucidar tal aspecto. ${ }^{16}$ Os problemas decorrentes da especialização também são objeto dos estudos de Edgar Morin, sobretudo no contexto do mundo globalizado, demostrando os equívocos de se conceber o estudo do direito desatrelado dos conteúdos desenvolvidos no âmbito de outros campos do conhecimento. ${ }^{17}$

\footnotetext{
${ }^{16}$ CASTRO, Cláudio de Moura. Crônicas de uma educação vacilante, 2005, p. 169-171: "Bernard Shaw disse que um especialista é uma pessoa que sabe cada vez mais sobre cada vez menos. A frase é engraçadinha, porém errada. Cadê o especialista que só sabe de um assunto? Certamente, não está nos empregos mais cobiçados. [...] [...] Portanto, o que conta não é o conhecimento especializado - inegavelmente necessário na pesquisa e em muitas outras áreas -, mas a combinação deste com uma série de competências generalizadas. Ou seja, todo especialista de primeira linha é também um excelente generalista. [...] [...] É interessante notar que as grandes multinacionais contratam "especialistas" para posições subalternas e, para boa parte das posições mais elevadas, pessoas com a melhor educação disponível, qualquer que seja o diploma. A profissionalização mais duradoura e valiosa tende a vir mais do lado genérico do que do especializado. Entender bem o que leu, escrever claro e comunicar-se, inclusive em outras línguas, são os conhecimentos profissionais mais valiosos. Trabalhar em grupo e usar números para resolver problemas, pela mesma forma, é profissionalização. E quem suou a camisa escrevendo ensaios sobre existencialismo, decifrando Camões ou Shakespeare pode estar mais bem preparado para uma empresa moderna do que quem aprendeu meia dúzia de técnicas, mas não sabe escrever. A lição é muito clara: o profissional de primeira linha pode ou não ser um especialista, dependendo da área. Pode ou não ter a necessidade de conhecer as últimas teorias da moda. Mas não pode prescindir dessa "profissionalização genérica", sem a qual será um idiota, cuspindo regras, princípios e números que não refletem um julgamento maduro do problema. Portanto, lembremonos: especialista não é quem sabe de um só assunto, e ser profissional não é apenas conhecer técnicas específicas. O profissionalismo mais universal é saber pensar, interpretar a regra e conviver com a exceção".

${ }^{17}$ MORIN, Edgar. Os sete saberes necessários à educação do futuro, 2000, p. 41-42: De fato, a hiperespecialização impede tanto a percepção do global (que ela fragmenta em parcelas), quanto do essencial (que ela dissolve). Impede até mesmo de tratar corretamente os problemas particulares, que só podem ser propostos e pensados em seu contexto. Entretanto, os problemas essenciais nunca são parcelados e os problemas globais são cada vez mais essenciais. Enquanto a cultura geral comportava a incitação à busca da contextualização de qualquer informação ou idéia, a cultura científica e técnica disciplinar parcela, desune e compartimenta os saberes, tornando cada vez mais difícil a sua contextualização. [...] $\mathrm{O}$ conhecimento especializado é uma forma particular de abstração. A especialização "abs-trai”, em outras palavras, extrai um objeto de seu contexto e de seu conjunto, rejeita os laços e as intercomunicações com seu meio, introduz o objeto no setor conceptual abstrato que é o da disciplina compartimentada, cujas fronteiras fragmentam arbitrariamente a sistemicidade (relação da parte com o todo) e a multidimensionalidade dos fenômenos; conduz à abstração matemática que opera de si própria uma cisão com o concreto, privilegiando tudo o que é calculável e passível de ser formalizado".
} 
Pozenato também refuta a proposta do ensino profissionalizante no âmbito universitário, conforme se depreende dos seus ensinamentos. ${ }^{18}$ Especificamente no contexto dos Cursos de Direito, Michel Miaille propõe um estudo transdisciplinar do Direito, superando uma perspectiva fraccionada da construção do processo ensino-aprendizagem. ${ }^{19}$

Os defensores da implementação do ensino baseado no modelo meramente profissionalizante-tecnicista no Curso de Direito alegam que os conteúdos desenvolvidos nas disciplinas do eixo de formação fundamental (por exemplo, Filosofia ou Sociologia) não são utilizados pelos advogados e demais operadores jurídicos para elaborarem suas petições e que o Curso de Direito não se presta a formar filósofos ou sociólogos, e que tal particularidade as torna prescindíveis na estrutura curricular. Para responder a esta alegação, as lições de Marilena Chaui acerca deste sofisma são por si só eloquentes, dispensando maiores comentários. ${ }^{20}$

Assim, a economia, por exemplo, que é a ciência social matematicamente mais avançada, é também a ciência social e humanamente mais atrasada já que se abstraiu das condições sociais, históricas, políticas, ecológicas inseparáveis das atividades econômicas. É por isso que seus peritos são cada vez mais incapazes de interpretar as causas e as consequiências das perturbações monetárias e das bolsas, de prever e de predizer o curso econômico, mesmo em curto prazo. Por conseguinte, o erro econômico torna-se a conseqüência primeira da ciência econômica. [...] "Um erro comum a muitos que freqüientam cursos universitários é o de pretender que a Universidade deva se preocupar exclusivamente com a habilitação profissional. Assim o candidato ao magistério quer aprender aquilo que vai utilizar na profissão futura, o candidato à administração quer conhecer as técnicas de administração que lhe são úteis, e assim por diante. Ocorre, porém, que em qualquer profissão há o perigo da cristalização. Um engenheiro altamente capacitado para o momento presente, se não souber progredir será amanhã um profissional defasado. Mais do que o treinamento profissional, é sobretudo a atitude investigadora o elemento mais importante do ensino superior. Na Universidade o aluno deverá aprender a investigar, saber qual é o significado e quais são as exigências da investigação para que possa, com esse impulso inicial, permanecer numa atitude de progresso científico".

${ }^{18}$ PAVIANI, Jayme e POZENATO, José C. Ibíd, p. 43: "Assim, pois, a interdisciplinariedade não pode fornecer resposta à nossa busca de uma ciência do direito que não seja outra coisa que não uma descrição das técnicas jurídicas. É preciso procurar para lá da pluridisciplinaridade; na direção daquilo que eu chamarei transdisciplinariedade, quer dizer, a ultrapassagem das fronteiras atuais das disciplinas. Esta ultrapassagem não significa que não existam objetos científicos legitimando investigações autômonas, mas que estes não têm existência senão num campo científico único [...] Afinal, é evidente que aparentemente o direito, a economia, a sociologia, a história são, não obstanteas incertezas das fronteiras, domínios bem marcados, bem diferentes; basta ver as reações dos estudantes assim que um jurista se põe a fazer economia ou que um historiador aborda problemas jurídicos; infringe uma divisão das disciplinas que parece impor-se pela simples lógica. A este respeito, a situação é idêntica em todas as ordens de ensino, como se a divisão do saber fosse coisa 'natural'. O direito é o direito, a economia é a economia. Eis ao que chegam, para lá das justificações mais rebuscadas, os nossos interlocutores. Pode-se mostrar os fatores econômicos da elaboração do direito e as condições econômicas da sua aplicação; poder-se-ia, inversamente, desenvolver o tema das condições jurídicas da vida econômica. Mas todos estes projetos não modificam o essencial. Ora o que me proponho a mostrar é que direito e economia, mas também política e sociologia, pertencem a um mesmo ‘continente' estão dependentes da mesma teoria, a da mesma história. É que direito e economia podem ser reportados ao mesmo sistema de referências científicas. Para admitir esta nova perspectiva é necessário abandonar o mito da divisão natural do saber. Este mito não é de papel: é um obstáculo, na medida em que é preciso forçálo, a fim de se conseguir obter os meios de traçar um caminho científico".

${ }^{19}$ MIAILLE, Michel. Introdução crítica ao direito, 1999, p. 61-62.

${ }^{20}$ CHAUI, Marilena. Convite à Filosofia, 2011, p. 13; 18: “[...] Essa pergunta, "Para que Filosofia", tem sua razão de ser. Em nossa cultura e em nossa sociedade, costumamos considerar que alguma coisa só tem o direito de existir se tiver alguma finalidade prática, muito visível e de utilidade imediata. Por isso, ninguém pergunta para que as ciências, pois todo mundo imagina ver a utilidade das ciências nos produtos da técnica, isto é, na aplicação científica da realidade. [...] Parece, porém, que o senso comum não enxerga algo que os cientistas sabem muito bem. As ciências pretendem ser conhecimentos verdadeiros, obtidos graças a procedimentos rigorosos de pensamento; pretendem agir sobre a realidade, através de 
Para refutar ainda este ponto de vista, são precípuos os ensinamentos de Pierre Bourdieu, constantes na aula inaugural proferida no Collège de France em 23 de abril de 1985: “[...] Se os que têm algo a ver com a ordem estabelecida, seja lá o que for, não gostam nem um pouco da sociologia, é porque ela introduz uma liberdade em relação à adesão primária que faz com que a própria conformidade assuma um ar de heresia ou de ironia". ${ }^{21}$

A ilação lógica a que se chega é que o antagonismo instaurado entre as disciplins do eixo de formação fundamental e das disciplinas profissionalizantes é uma falácia, pois como vimos anteriormente, todas elas são importantes e todas contribuem para a formação dos bacharéis de Direito. ${ }^{22}$ Além disso, a formação humanista, reflexiva e crítica não é apenas uma meta das disciplinas do eixo de formação fundamental, uma vez que todas as disciplinas da estrutura curricular são responsáveis por tal formação, assim como constitui missão das disciplinas dos eixos de formação profissional e prática contextualizarem seus conteúdos com situações concretas da realidade social e jurídica.

instrumentos e objetos técnicos; pretendem fazer progressos nos conhecimentos, corrigindo-os e aumentando-os. Ora, todas essas pretensões das ciências pressupõem que elas acreditam na existência da verdade, de procedimentos corretos para bem usar o pensamento, na tecnologia como aplicação prática de teorias, na racionalidade dos conhecimentos, porque podem ser corrigidos e aperfeiçoados. Verdade, pensamento, procedimentos especiais para conhecer fatos, relação entre teoria e prática, correção e acúmulo de saberes: tudo isso não é ciência, são questões filosóficas. O cientista parte delas como questões já respondidas, mas é a Filosofia quem as formula e busca respostas para elas. Assim, o trabalho das ciências pressupõe, como condição, o trabalho da Filosofia, mesmo que o cientista não seja filósofo. No entanto, como apenas os cientistas e filósofos sabem disso, o senso comum continua afirm ando que a Filosofia não serve para nada. [...] $\mathrm{O}$ primeiro ensinamento filosófico é perguntar: O que é útil? Para que e para quem algo é útil? O que é o inútil? Por que e para quem algo é inútil? O senso comum de nossa sociedade considera útil o que dá prestígio, poder, fama, riqueza. Julga o útil pelos resultados visíveis das coisas e das ações, identificando utilidade e a famosa expressão "levar vantagem em tudo". Desse ponto de vista, a Filosofia é inteiramente inútil e defende o direito de ser inútil. Não poderíamos, porém, definir o útil de outra maneira? [...] Qual seria, então, a utilidade da Filosofia? Se abandonar a ingenuidade e os preconceitos do senso comum for útil; se não se deixar guiar pela submissão às idéias dominantes a aos poderes estabelecidos for útil; se buscar compreender a significação do mundo, da cultura, da história for útil; se conhecer o sentido das criações humanas nas artes, nas ciências e na política for útil; se dar a cada um de nós e à nossa sociedade os meios para serem conscientes de si e de suas ações numa prática que deseja a liberdade e a felicidade para todos for útil, então podemos dizer que a Filosofia é o mais útil de todos os saberes de que os seres humanos são capazes".

${ }^{21}$ BOURDIEU, Pierre. Lições de Aula, 2003, p. 60.

${ }^{22}$ MIAILLE, Michel, Ibíd, p. 57-58, elucida esta particularidade ao analisar os cursos jurídicos na França: "Hoje em dia, os conhecimentos transmitidos por altura deste primeiro ano encontram-se repartidos por vários domínios: do direito, claro (direito civil, direito constitucional e direito internacional), da economia, política e da história. O volume horário destinado a cada uma destas disciplinas é rigorosamente idêntico: todas as cadeiras são anuais, que dizer, dão lugar ao mesmo número de horas. Estas matérias rapidamente aparecem pois como equivalentes, ainda que bem diferenciadas pela clivagem que se estabelece entre as matérias jurídicas e as que não são (história e economia), às quais depressa se confere o caráter de 'cultura geral'. Finalmente, institui-se entre estes dois blocos uma espécie de status quo pacífico: cada uma destas disciplinas destina-se a elevar o nível e a qualidade dos conhecimentos dos estudantes, mas de forma separada, e continua a entender-se que, de qualquer modo, a boa formação de um jurista requer a sua especialização e, portanto, o abandono progressivo das matérias de "cultura geral' - o que é feito à medida que se progride no decurso dos anos da licenciatura. Afinal de contas, se não estou muito documentado sobre as instituições jurídicas da monarquia absoluta ou sobre a lei da oferta e da procura, que importância tem isso para um jurista? Por outras palavras, a repartição entre as matérias do primeiro ano depressa se analisa como uma repartição; [...]" 
Como se pode perceber, os defensores do modelo profissionalizante-tecnicista adotam uma atitude maniqueísta, olvidando os malefícios que a referida proposta causou no passado para a formação dos bacharéis de Direito. ${ }^{23}$

A partir de tais reflexões, fica evidente que o argumento da especialização dos bacharéis em Direito, em decorrência do ensino profissionalizante, encontra-se superado, por tratar-se de um modelo ultrapassado e que não atende aos objetivos acadêmicos, muito menos às expectativas do perfil desejado dos egressos dos alunos do ensino superior previstas pelas diretrizes curriculares estabelecidas pelo Ministério da Educação.

\section{Desafios didáticos e propostas de metodologia de ensino da Sociologia do Direito nos Cursos de Direito no Brasil}

Como se infere no novo panorama apresentado nos itens anteriores, a implementação das diretrizes curriculares trouxe propostas para viabilizar a ruptura com o modelo de ensino jurídico tecnicista que vigorava até então. Todavia, obviamente, a inclusão de disciplinas e/ou conteúdos constantes no eixo de formação fundamental não garantem, por si sós, um perfil interdisciplinar do Curso de Direito.

Para que tal proposta possa vingar, é necessário muito mais do que isso. Caso contrário, estaríamos apenas satisfeitos com os aspectos formais, pois as disciplinas e conteúdos de formação humanística na estrutura curricular seriam ministrados de forma estanque, sem comunicação com a formação jurídica e com o viés crítico e reflexivo atinente à realidade brasileira, consoante os objetivos das diretrizes curriculares. Seria algo "para inglês ver", como diz o dito popular e/ou esteticamente "bonito" quando se vislumbra a estrutura curricular do Curso.

Primeiramente, é importante verificar o panorama dos estudantes que ingressam nos Cursos de Direito. Vislumbra-se que os alunos ingressam com 17/18 anos de idade e percebe-se que não tem ainda maturidade suficiente (salvo raras exceções) para assimilarem a proposta das diretrizes curriculares do ensino jurídico, as quais preconizam transcender o mero conhecimento das leis e de sua interpretação. Normalmente, eles sequer cogitam que a formação do ensino superior deva ir muito além da formação

\footnotetext{
23 Neste particular, é relevante resgatar os ensinamentos de Edgar Morin, acerca das consequências perniciosas do conhecimento fragmentado no livro MORIN, Edgar. A cabeça bem-feita: repensar a reforma, reformar o pensamento, 2004, p. 14-15: "Efetivamente, a inteligência que só sabe separar fragmenta o complexo do mundo em pedaços separados, fraciona os problemas unidimensionalmente o multidimensional. Atrofia as possibilidades de compreensão e de reflexão, eliminando assim as oportunidades de um julgamento corretivo ou de uma visão a longo prazo. Sua insuficiência para tratar nossos problemas mais graves constitui um dos mais graves problemas que enfrentamos. De modo que, quanto mais os problemas se tornam multidimensionais, maior a incapacidade de pensar sua multidimensionalidade; quanto mais a crise progride, mais progride a incapacidade de pensar a crise; quanto mais planetários tornam-se os problemas, mais impensáveis eles se tornam. Uma inteligência incapaz de perceber o contexto e o complexo planetário fica cega, inconsciente e irresponsável. Assim, os desenvolvimentos disciplinares das ciências não só trouxeram as vantagens da divisão do trabalho, mas também os inconvenientes da superespecialização, do confinamento e do despedaçamento do saber. Não só produzimos o conhecimento e a elucidação, mas também a ignorância e a cegueira".
} 
técnica. ${ }^{24}$ Isso gera, desde o início, via de regra, um desinteresse em larga escala dos estudantes com relação às disciplinas do eixo de formação fundamental: eles querem estudar Direito, ou seja, manusear os códigos e estudar a partir deles desde o primeiro dia de aula e ficam frustrados quando se defrontam com as disciplinas ministradas no primeiro ano do Curso de Direito, por não lhes propiciarem tão expectativa.

A postura dos alunos dentro deste quadro é acomodar-se, resignar-se a aceitar a realidade adversa às suas expectativas, e meramente cumprir as etapas necessárias para serem aprovados nas disciplinas do eixo de formação fundamental. Alguns lamentam, inclusive, a "perda de tempo" que tais disciplinas representam, eis que seus conteúdos não são objeto dos exames para ingresso na Ordem dos Advogados do Brasil ou para os concursos para as carreiras jurídicas 2526.

A partir deste panorama é possível constatar as consideráveis dificuldades que, de plano, os professores das disciplinas do eixo fundamental se defrontam. A despeito de tais vicissitudes, acreditamos que os objetivos das diretrizes curriculares poderão ser alcançados, primeiramente, considerando a escolha do perfil do professor que ministra a disciplina e com as propostas de metodologia de ensino por ele utilizadas. Tais peculiaridades são fundamentais para superar os desafios que os professores das referidas disciplinas enfrentam perante as expectativas dos estudantes de Direito. ${ }^{27}$

\footnotetext{
${ }^{24}$ Neste particular assevera Antônio Alberto Machado, Ibíd, p. 68: “[...] Atinge o ensino jurídico porque este não está mais orientado por padrões didáticos e pedagógicos que propiciem a formação completa do jurista, capacitando-o para atuar em meios sociais conflitivos, como mediador de relações que devem orientar pela busca da justiça e da democracia, enquanto expressões de igualdade social e participação política; e atinge também a atuação profissional do jurista, porque essa atuação há muito se tornou um fazer simplesmente tecnológico, despolitizado e exercido com total indiferença pelos critérios de justiça, quer distributiva, que comutativa".

${ }^{25}$ Os efeitos negativos deste panorama são assim apresentados por Antônio Alberto Machado, op. cit., p. 81: "Com efeito, a apreensão do fenômeno jurídico, vem como a prática legal transmitida pela didática instituída, estão fortemente apegadas aos códigos e devotam um absurdo desprezo pelas regiões anômicas e valorativas do direito. O ensino e a prática passam a gravitar apenas em torno do problema da decidibilidade técnico-processual. E esta, por sua vez, reduz a ciência do direito à mera técnica de eliminar conflitos, sempre numa perspectiva privatística, sem a necessária preocupação com o conteúdo social e com os efeitos políticos das decisões. Isso indica a maneira pela qual o modelo pedagógico, a metodologia e o paradigma epistemológico da ciência do direito mergulharam na profunda crise de legitimidade em que se encontram, com graves reflexos na formação dos bacharéis e profissionais do direito, cuja cultura técnico-profissional dispensa completamente a visão política do fenômeno jurídico".

${ }^{26}$ No mesmo diapasão, vide a crítica desta concepção formulada por Duncan Kennedy no capítulo 2 - La enseñanza del derecho en el primero año como acción política, no livro La enseñanza del derecho como forma de acción política, KENNEDY, Duncan. La enseñanza del derecho: como forma de acción política, 2012, p. 43-60.

${ }^{27}$ Para explicitar a importância e a necessidade das disciplinas do eixo de formação fundamental, transcendendo o caráter utilitário e técnico da formação a ser propiciada pelos cursos jurídicos, podemos utilizar, por analogia, os mesmos argumentos esclarecedores presentes nas lições de Maria Lúcia de Arruda Aranha e Maria Helena Pires Martins, no livro "Filosofando", 2009, p. 16-17: [...] "Afinal, qual é a 'utilidade' da filosofia? Vivemos num mundo que valoriza as explicações imediatas do conhecimento. O senso comum aplaude a pesquisa científica que visa a cura do câncer ou da aids; a matemática no ensino médio seria importante por 'cair' no vestibular; a formação técnica do advogado, do engenheiro, do fisioterapeuta prepara para o exercício dessas profissões. Diante disso, não é raro de alguém indague: Para que estudar filosofia se não vou precisar dela na minha vida profissional? De acordo com esta linha de pensamento seria realmente `inútil’, já que não serve para qualquer alteração imediata de ordem prática. No entanto, a filosofia é necessária. Por meio daquele 'olhar diferente', ela busca outra dimensão da realidade além das necessidades imediatas nas quais o indivíduo encontra-se mergulhado: ao tornar-se capaz de superar a situação dada e repensar o pensamento e as ações que ele
} 
Diferentemente dos Cursos das Áreas de Ciências Humanas, os professores das disciplinas do eixo fundamental raramente possuem uma formação específica nas disciplinas específicas que ministrarão. Em outras palavras, professores designados para ministrarem os conteúdos de Antropologia, Ciência Política, Economia, Ética, Filosofia, História, Psicologia e Sociologia dificilmente possuem uma formação específica nestas áreas quando da sua formação em pós-graduação em Direito strito sensu (Mestrado e/ou Doutorado).

Em face da crescente proliferação de cursos jurídicos a partir da segunda metade da década de 90 , visando atender à necessidade de suprir a demanda de professores para a disciplina do eixo de formação fundamental, houve equivocamente a contratação de muitos professores "improvisados", normalmente de áreas "congêneres" ou até mesmo de áreas sem qualquer afinidade apenas para "quebrar um galho". Trata-se de docentes que têm o conhecimento dos conteúdos obrigatórios a serem desenvolvidos pelas disciplinas do eixo de formação fundamental, a partir de uma disciplina que cursaram na sua formação no ensino superior.

Por este motivo, entendemos que em face das adversidades encontradas pelos professores decorrentes da pouca aceitação dos alunos com relação às disciplinas do eixo de formação fundamental, é imprescindível a contratação de professores com formação jurídica com interlocução nas áreas específicas que irão atuar (Antropologia, Ciência Política, Economia, Ética, Filosofia, História, Psicologia e Sociologia), eis que certamente estarão mais capacitados para ministrar a disciplina e demonstrar sua importância e necessidade para a formação dos estudantes do Direito, especialmente para enfatizar que a abordagem interdisciplinar amplia significativamente o conhecimento do Direito, deixando de vê-lo como algo autônomo à sociedade, mas que na verdade é produto dela e que se encontra em constante conexão com outros campos do saber. ${ }^{28}$

No mesmo diapasão, é essencial que os professores da disciplina do eixo de formação fundamental, independentemente de serem Mestres ou Doutores, tenham na sua formação conhecimento da Didática do Ensino Superior e da Metodologia do Ensino Superior ${ }^{29}$ para estarem capacitados para introduzir

desencadeia, o indivíduo abre-se para a mudança. Tal como o artista, [...], ao filósofo incomoda o imobilismo das coisas feitas e muitas vezes ultrapassadas. Por isso mesmo, a filosofia pode ser 'perigosa', por exemplo quando desestabiliza o status quo ao se confrontar com o poder. [...]"

28 As consequências negativas da ausência ou rejeição deste ponto de vista são assim apresentadas por Antônio Alberto Machado, Ibíd., p. 82: "Tal prática pedagógica, em muitos casos levado a efeito por professores sem preparo didático e científico, entroniza o racionalismo dogmático como ideologia jurídica oficial e expulsa da cátedra jurídica todo tipo de abordagem crítico-didática estimulada pelo meio social conflitivo e em constante mudança onde vai se operar o saber/fazer jurídico. É precisamente assim que a prática pedagógica instala uma enorme distância entre o conhecimento dogmático do direito e a percepção das urgências cada vez mais complexas da realidade social e política. A leitura e o ensino dos códigos, de modo acrítico e irreflexivo, completamente desvinculado de suas condicionantes sociais e econômicas, acabam mesmo por reproduzir, no plano jurídico, uma certa lógica de controle e dominação social que já está previamente formalizada nos estatutos legais".

${ }^{29}$ Temos conhecimento que para os alunos bolsistas da CAPES, a realização da Prática de Docência é um requisito para auferir a bolsa e que, para tanto, basta o pós-graduando ministrar aulas substituindo seus orientadores. Todavia, a disciplina Prática de Docência deve estimular o conhecimento da Didática e da Metodologia do Ensino superior e não serem apenas um mecanismo de delegar a atribuição didática aos pós-graduandos, eis que a prática de docência pressupõe o domínio da teoria (didáticas e metodologia do ensino) e esta não se restringe somente ao conteúdo das aulas a serem ministradas. 
novas práticas metodológicas além daquelas tradicionalmente disseminadas nos Cursos de Direito, vale dizer, as aulas expositivas e o comentário enjoativo de artigos de códigos. Trata-se de uma ruptura do modelo "quem sabe, sabe ensinar" e "o bom professor nasce feito" cuja competência para ensinar estava apenas e unicamente centrada na sua competência profissional fora do âmbito acadêmico. ${ }^{30}$

Antes de ingressarmos na apreciação das propostas de metodologias de ensino para o ensino das disciplinas do eixo de formação fundamental, o professor da disciplina deve ter conhecimento das principais das teorias educacionais e, a partir da sua definição, adotar estratégias para adequação à sua prática didática.

Para identificar compreender as principais teorias educacionais, valemo-nos dos estudos de Paulo Ghirardelli Jr. ${ }^{31}$, o qual os enquadra em três paradigmas (no sentido de Kuhn) e elege os principais representantes de cada um deles: o discurso educacional humanista (Herbart), o discurso educacional da sociedade do trabalho (Dewey) e propõe a superação de ambos com o paradigma "pós-moderno" 32 ou "pós-narrative turn" (concebido por Ghirardelli).

Em face das limitações da dimensão do artigo, iremos nos concentrar na análise do último paradigma, o qual entendemos nos trará subsídios para fundamentar as propostas metodológicas das disciplinas do eixo de formação fundamental, particularmente da disciplina Sociologia do Direito.

Segundo Paulo Ghirardelli Jr., o paradigma da "teoria educacional pós-moderna"” ou "pós-narrative turn" seria constituído de cinco passos: 1) apresentação de problemas; 2) articulação entre os problemas apresentados e os problemas da vida cotidiana; 3) discussão dos problemas através de narrativas tomadas sem hierarquização epistemológica; 4) formulação de novas narrativas; 5) ação cultural, social e política.

À luz das características do paradigma em tela, percebe-se a importância do âmago das práticas didáticas estarem focadas na "articulação entre os problemas apresentados e os problemas da vida cotidiana". ${ }^{33}$

Portanto, a disciplina Prática de Docência deve conciliar, concomitantemente, os saberes didático-pedagógicos e o conhecimento dos conteúdos da disciplina a serem transmitidos e não apenas os últimos.

${ }^{30}$ GIL, Antônio Carlos. Didática do ensino superior, 2009, p. 19.

${ }^{31}$ GHIRALDELLI JR., Paulo. Didática e teorias educacionais. 2000.

32 Em que pese a controvérsia da existência da pós-modernidade, dentre as teses do fenômeno modernidade/pósmodernidade, Ricardo Maliandi, no livro "Dejar la posmodernidad: la ética frente al irracionalismo actual”, 1993, p. 9, sustenta a existência entre outras, de uma tese de que a modernidade ainda não morreu ou se esgotou e a avalia positivamente: “[...] 4) o positivo de nossa época é que a modernidade todavia não morreu”.

${ }^{33}$ É importante, neste particular, o esclarecimento feito por GHIRARDELLI, Paulo, Ibíd., 57: “[...] Aliás, neste passo, há uma maior distinção entre a didática pós-moderna e a didática herdeira das tendências críticas como a de Paulo Freire. Trata-se da desvinculação entre o pensamento educacional pós-moderno e o movimento crítico em educação. A ideia da crítica, em sentido forte, pressupõe a ideia metafísica de que existiria uma realidade última capaz de ser desvelada, justamente, pela crítica. Em razão disso, educação, nesta perspectiva, seria 'iluminação', 'desideologização', 'desalienação' etc. (a catequização invertida!). [...] 
Isso significa, primeiramente, que os professores das disciplinas do eixo de formação fundamental devem evitar a transmissão dos conteúdos por mero diletantismo, apresentando as teorias sociológicas de forma "pasteurizada", recitando conceitos e repetindo-os como um mantra, sem qualquer conexão com a realidade vivenciada contemporaneamente.

Os professores de tais disciplinas devem estar comprometidos com a construção de um processo ensino-aprendizagem pautado com a articulação, sempre que possível, entre os conhecimentos da área específica do conhecimento e a perspectiva jurídica, pois afinal de contas se tratam de estudantes de Direito e não de Ciências Sociais, Filosofia ou História e, obviamente, tal peculiaridade deve ser considerada para que as aulas ministradas despertem o interesse dos alunos.

Tendo tais pressupostos como norte, considerando as limitações da extensão do artigo, apresentaremos três propostas metodológicas (as aulas expositivas, a elaboração de fichas de leitura e a realização de estudos dirigidos) e a avaliação (particularmente a realização de provas), as quais são experiências desenvolvidas em sala de aula. ${ }^{34}$

Em primeiro lugar, em se tratando das aulas expositivas, é necessário fazer algumas mediações para que sua abordagem não seja maniqueísta ${ }^{35}$, tanto positiva quanto negativamente, como via de regra se constata nas suas apreciações.

É inquestionável a importância das aulas expositivas ${ }^{36}$, considerando que ainda não se concebeu um mecanismo de transmissão de um considerável número de informações em tempo reduzido. Ademais, tendo como referência que os professores ministram aulas para turmas de no mínimo 50 alunos e até 100 alunos (ou mais), o desenvolvimento e o cumprimento na integralidade dos conteúdos das unidades do plano de ensino ficariam seriamente comprometidos na hipótese de adotarem, em todas as aulas, outras metodologias de ensino, tais como seminários, estudo de casos, discussão de textos, as quais implicam grupos reduzidos de alunos para que as dinâmicas de participação possam ser atendidas, além do tempo necessário para realizá-las.

Todavia, ministrar aulas não se restringe a apenas e tão somente transmitir informações e, consoante o paradigma "pós-moderno" de Ghirardelli Jr., envolve também a articulação de problemas com a vida cotidiana. ${ }^{37}$ Entendemos que a proposta metodológica de Álvaro Melo Filho acerca da aula expositiva dialogada apresenta requisitos significativos que para possibilitar o atingimento de tal meta. ${ }^{38}$

\footnotetext{
${ }^{34}$ Nas turmas da disciplina Direito e Sociedade, desde 1998, no Curso de Direito da Universidade Federal do Paraná.

${ }^{35}$ Acerca das vantagens e as limitações da aula expositiva, vide GIL, Antônio Carlos. Ibíd., p. 137-138.

${ }^{36}$ É importante destacar, todavia, que nos Cursos de Direito, desde a sua criação em 1827, que constitui um habitus a prática da "aula conferência", onde não é permitida qualquer interrupção na elocução do professor. Neste particular, indicamos a leitura de nosso artigo $\mathrm{O}$ discurso jurídico no contexto dos Cursos de Direito no Brasil: reflexões a partir das teorizações de Pierre Bourdieu, "in” FONSECA, Ricardo Marcelo (org.). Direito e discurso: discursos do direito. ed. Fundação Boiteux, Florianópolis, p. 105-122. http://pt.scribd.com/doc/104526079/O-discurso-juridico-no-contexto-doscursos-de-direito-no-Brasil-reflexoes-a-partir-das-teorizacoes-de-Pierre-Bourdieu - consulta 15 de junho de 2015.

37 "Passo 2. Na sequência, o processo ensino-aprendizagem visa relacionar as situações problemáticas e os problemas propriamente ditos com os problemas da vida cotidiana dos estudantes, dos seus avós e pais, enfim, do seu grupo social ou familiar ou de amigos, e até mesmo do seu país - presente, passado e futuro. Aqui, o estudante é convidado a ser um
} 
Para possibilitar a participação dos estudantes, o professor deve, sempre que possível, expor o conteúdo estabelecendo conexões com situações concretas da realidade cotidiana, problematizando-os, fazendo mediações entre a Sociologia e o Direito e vice-versa, para que os alunos percebam a importância e necessidade do conhecimento que lhes é transmitido, mas também se sentirem estimulados não apenas a refletirem sobre o mundo que os cerca, mas também e sobretudo, para uma postura crítica e participativa, caracterizada pela constante indagação e não como mero coadjuvante e expectador passivo perante os acontecimentos e/ou como mero "depósito" das informações transmitidas pelo professor.

Para cumprir o seu papel, exige-se do professor da disciplina Sociologia do Direito estar sintonizado com os acontecimentos cotidianos, sempre atualizado com aquilo que está "acontecendo", seja na mídia, na música, no cinema, nas histórias em quadrinhos, nas redes sociais, nos julgamentos dos Tribunais como muito bem destacou Ghirardelli Jr. no Passo $3{ }^{39}$ do seu paradigma "pós-moderno". Por outro lado, verificamos a árdua dificuldade para estimular a participação dos alunos ${ }^{40}$, o que constitui um constante desafio para o professor da disciplina, o qual deve estar sempre motivado para

personagem da narrativa contada no passo anterior e, ao mesmo tempo, um filósofo, isto é, segundo Nietzsche, um juiz dos desdobramentos internos da narrativa. [...]"

${ }^{38}$ FILHO, Álvaro Melo. Metodologia do ensino jurídico, 1984, p. 104: “1) Diálogo construtivo: estabelece relação de Integração/Liberdade - Ação bilateral implicando em relacionamento; 2) Centrada no Aluno Utilitarismo altruísta do Professor; 3) Alunos ativos, autônomos e estimulados à participação; 4) A verdade não tem proprietário; 5) Visa a despertar o raciocínio jurídico; 6) Oportuniza a visão crítica e aguça nos alunos a capacidade de resolver problemas - Desperta a reflexão crítica; 7) Diversidade metodológica própria das sociedades heterogêneas; 8) Apoia-se numa visão experiencial e pragmática do Direito; 9) Enseja conciliar-se a teoria e prática jurídicas; 10) Direito é apresentado como algo dinâmico e mutável (conhecimento aberto)".

39 "Passo 3. O terceiro momento é o de redescrição das narrativas nas quais os problemas estavam inseridos; dá-se através de outros tipos de narrativa - de ordem ficcional, histórica, científica e filosófica. O importante é que o estudante perceba que essas narrativas que redescrevem as primeiras não estão hierarquizadas epistemologicamente. Não há uma narrativa que apreende a realidade como ela é. Mas há, em cada uma, jogos de linguagem distintos que estão aptos, pragmaticamente, para uma coisa e não para outra. [...] A redescrição de um filme ou de uma história em quadrinhos não necessariamente precisa ser outro filme ou outra história em quadrinhos, pode ser um texto filosófico ou científico - até é bom que seja assim, contanto que não façamos a sociologização de Machado de Assis, como fez uma geração de marxistas, denegrindo a obra. O importante é o entendimento de que essa redescrição não está ali para desvendar o que havia de essencial e de verdadeiro na primeira narrativa. Não há uma chave para se chegar mais próximo da realidade, como não há uma chave para desvendar a interpretação correta. [...] Na tradição 'crítica', a educação sempre foi derivada do platonismo: sempre esteve ligada à ideia da fuga do prisioneiro da caverna que, ao ver a luz do sol, encontra a "verdadeira" realidade" e se livra do "mundo das sombras" - como na Alegoria da Caverna, que está na República, de Platão. No movimento pós-moderno, esse chão metafísico é considerado inútil, pois todas as narrativas são distinguíveis não por estarem umas mais, outras menos enganchadas no 'mundo', mas sim, por serem umas mais úteis, e outras menos úteis segundo nosso expediente. Dispensa-se a ontologia, portanto. Não há uma narrativa que tocaria o chão ontológico mais que outra. Assim, a educação, na didátíca pós-moderna, fornece passos através dos quais professores e alunos podem realmente caminhar juntos, aplicando as narrativas a uma agenda de expedientes construída em comum, sem que o professor tenha a missão de 'desalíenar' o aluno".

${ }^{40}$ Indicamos a leitura do livro "O Y da questão: como a geração Y está transformando o mercado de trabalho", de LANCASTER, Lynne e STILLMANN, 2011, 264 p., no qual os autores discorrem sobre Geração Y (dos nascidos a partir 1982) e os seus conflitos com as gerações anteriores, bem como os seus motivadores de sentido para estimular sua participação: (1) quer fazer a diferença no mundo; 2) quer ter a sensação de que está contribuindo; 3) quer ser inovadora; 4) quer ser ouvida; 5) quer saber que está se saindo bem; 6) quer se expressar por meio do trabalho). 
aprimorar os mecanismos para tal propósito, a despeito das experiências frustradas que tenha vivenciado.

Outro aspecto metodológico que deve ser levado em consideração, diz respeito à superação de uma carência enfrentada pelos professores e alunos da disciplina Sociologia do Direito. Em que pese uma prolífica quantidade de Manuais e Cursos da disciplina, eles têm em comum a superficialidade das abordagens; alguns não transcendem além da leitura dos clássicos (Durkheim, Marx e Weber) e outros reproduzem, com poucas variações, o "formato" dos livros da mesma natureza da disciplina de Sociologia dos vários Cursos onde ela integra o currículo, ou seja, apresentando os capítulos a partir de temas (exemplos: sociedade, controle social, estratificação social, violência, etc.). Com tal análise, não queremos afirmar a impossibilidade de fazê-lo desta forma, porém, acreditamos que o estudo da Sociologia do Direito é muito mais profícuo quando é realizado a partir da produção teórica dos sociólogos que, no bojo das suas teorizações, também refletiram o Direito, em decorrência do acesso direto às fontes primárias (os originais).

Considerando tais dificuldades, realizamos a indicação bibliográfica para os alunos, de cada uma das unidades do programa de ensino, compreendendo fontes primárias e secundárias e os estimulamos ${ }^{41}$ a produzirem fichas de leitura ${ }^{42}$ de resumo a partir de textos indicados das fontes primárias. Desta forma, há uma complementação dos conhecimentos auferidos em sala de aula e desenvolve-se a habilidade para leitura, bem como para a capacidade de concisão para identificar e expor as ideias principais dos textos que foram lidos. Acrescente-se ainda, a progressiva melhora dos estudantes no desenvolvimento da exposição escrita das suas ideias, sobretudo no aprimoramento progressivo da argumentação dos alunos das respostas para as questões apresentadas nas provas. ${ }^{43}$

Porém, tal metodologia também não está imune à aversão dos estudantes, que a identificam como uma atividade penosa e maçante, sendo muitas vezes objeto de troça nas redes sociais, sendo que alguns o fazem porque "vale nota" e/ou outros optam por realizar a ficha de leitura cuja nota vale a pena.

\footnotetext{
${ }^{41} \mathrm{O}$ conjunto das fichas de leitura representa um percentual em torno de $20 \%$ de cada avaliação. Para a análise das fichas de leitura, face à sua expressiva quantidade, deverá o professor contar com o auxílio dos monitores da disciplina, os quais também poderão auxiliar os alunos para dirimirem as dúvidas acerca da compreensão dos textos objeto das fichas de leitura. 42 Tratam-se de atividades desenvolvidas fora de sala de aula, com a proposição de tarefas de leitura. No que tange a esta metodologia, vide GIL, Antônio, Ibíd., p. 201-203.

43 A leitura de livros e/o capítulos de livros constitui uma ruptura radical com a "cultura" das apostilas, fartamente disseminada no ensino médio, as quais se abstêm a meramente apresentar sínteses com informações e/ou dicas sobre o tema estudado, visando à preparação para as provas que seguem um modelo que apenas "cobra" tais peculiaridades e também (e quem sabe sobretudo) constituem um "treinamento" para as provas do vestibular. Por outro lado, outra prática acaba se disseminando entre os estudantes universitários: a utilização coletiva para estudo do caderno "da turma" (batizamos de caderno da "escriba da sala"), o qual via de regra é produzido por uma estudante que se encarrega de registrar as informações das aulas expositivas (há inclusive versões digitalizadas e disponibilizadas aos alunos na internet). Entendemos que não há, num primeiro momento, uma prática negativa do uso desta tradição, todavia os maiores benefícios são auferidos por aqueles que são os autores do caderno. Entretanto, compreendemos que seria muito mais construtivo para os alunos da turma aprimorarem o caderno "da turma" como anotações próprias e de leituras realizadas, do que apenas e tão somente têlo como única referência para estudar como normalmente acontece. Acerca de deste assunto, vide a seguinte reportagem: http://www.gazetadopovo.com.br/vida-universidade/nocampus/conteudo.phtml?tl=1\&id=1256235\&tit=Caderno-que-passade-mao-em-mao - consulta 31 de agosto de 2012.
} 
Malgrado tal postura, cabe ao professor constantemente relembrar aos alunos os motivos da utilização da metodologia e os benefícios que elas propiciarão para a formação dos estudantes.

Em consonância com o Passo 2 da proposta metodológica de ensino de Ghirardelli Jr, elaboramos estudos dirigidos ${ }^{44}$, os quais denominamos exercícios de fixação e que têm por escopo atuarem como um mecanismo de revisão das unidades do plano de ensino, bem como para possibilitar que os estudantes identifiquem suas dificuldades e para preparar os alunos para as provas. ${ }^{45}$ A aplicação dos estudos dirigidos pode ocorrer em sala de aula (realizado em pequenos grupos para possibilitar a participação de todos e a troca de ideias) ou para ser resolvido individualmente e/ou em grupos fora de sala de aula e, posteriormente, corrigido coletivamente.

Acerca da elaboração dos estudos dirigidos é fundamental que eles sejam produzidos tendo como meta a contextualização e a problematização com fatos da vida cotidiana (Passo 3). Portanto, deve-se abandonar qualquer iniciativa de meramente fazer um rol de perguntas para tão somente aferir informações sobre os conteúdos ministrados em sala de aula.

Para tal tarefa, o professor da disciplina Sociologia do Direito deve estar sempre sintonizado com os acontecimentos atuais e procurar integrá-los na problematização dos exercícios de fixação. Trata-se de um mecanismo para estimular os alunos a resgatarem os objetivos das unidades estudadas, para revisitarem os conteúdos estudados e contextualizá-los com situações concretas do cotidiano, contribuindo não apenas para o aprendizado, mas também para que os alunos percebam a importância e necessidade daquilo que foi estudado, os quais os capacitam para fazerem uma leitura do mundo além da apreciação do senso comum.

No que tange às avaliações, particularmente a elaboração de provas ${ }^{46}$, primeiramente, elas não devem ser vistas como o final do processo ensino-aprendizagem, mas como mais uma etapa do processo ${ }^{47} \mathrm{e}$

\footnotetext{
44 Indicamos a leitura de HAIDT, Regina Célia Cazaux, 1995, p. 159-164, no qual é apresentada a metodologia desta atividade.

${ }^{45}$ Em consonância com as orientações de GIL, Antônio Carlos, Ibíd., p. 251.

46 Acerca da avaliação e sua metodologia, recomendamos a leitura de GIL, Antônio Carlos, Ibíd., pp. 239-265 bem como do livro "Avaliação: mito \& desafio - uma perspectiva construtivista" de Jussara Hoffmann, 1993, p. 9-81 e, especialmente no contexto dos Cursos de Direito, Álvaro Melo Filho, Ibíd., pp. 123-148.

${ }^{47}$ Nesta perspectiva, GIL, Antônio Carlos, Ibíd., pp. 246-247, ressalta que a avaliação deve ser entendida como parte integrante do processo de aprendizagem: "Numa escola concebida para servir a uma sociedade moderna, a avaliação deixa de ser vista como instrumento de seleção e de fiscalização, externo ao processo de aprendizagem, e passa a ser vista como um método de coleta e análise dos dados necessários à melhoria da aprendizagem dos alunos, e como parte integrada e essencial desse processo. A avaliação auxilia na aprendizagem por meio dofeedback $e$ da motivação. Os resultados dos testes informam o estudante acerca de seus sucessos e fracassos, das etapas vencidas e das dificuldades encontradas. Um exame bem elaborado auxilia realmente o ensino, já que estimula a refletir sobre os conceitos de uma forma nova e a perceber novas relações entre eles. Com efeito, poucas coisas podem ser tão importantes para estimular os estudantes a dominar o conteúdo das matérias quanto um exame rigoroso. Os resultados dos testes também são úteis para informar os professores acerca do quanto o ensino oferecido tem sido eficaz, contribuindo para a redefinição e o ordenamento dos conteúdos e adequação das estratégias para facilitar a aprendizagem".
} 
propiciam um "feedback para o professor" 48 que, portanto, devem ser cuidadosamente preparadas para que possam atingir tal objetivo.

Em segundo lugar, mas não menos importante, as provas devem ser produzidas em consonância com os Passos 2 e 3 da proposta metodológica formulada por Ghirardelli Jr., ou seja, "articulação entre os problemas apresentados e os problemas da vida cotidiana" e "discussão dos problemas através de narrativas tomadas sem hierarquização epistemológica". Talvez seja desnecessário fazer menção, mas há uma "tradição" nos Cursos de Direito que as provas são produzidas visando única e exclusivamente o domínio da memorização, ou seja, aferir a capacidade de retenção das informações dos alunos ${ }^{49}$ e a proposta visa superar esta limitação.

Neste particular identifica-se, provavelmente, o maior desafio a ser enfrentado pelos professores da disciplina Sociologia do Direito. Em primeiro lugar, por terem que assumir uma postura heterodoxa em descompasso com a tradicional prática da prova dissertativa que meramente contém perguntas que visam aferir a capacidade de memorização e reprodução das informações. Em segundo lugar, porque a elaboração das provas exigirá um trabalho árduo ${ }^{50}$ de pesquisa, de dedicação de tempo e, sobretudo, de estímulo à criatividade.

O trabalho de pesquisa consiste na busca de situações da vida cotidiana (na mídia, na música, no cinema, nas histórias em quadrinhos, nas redes sociais, nos julgamentos dos Tribunais) para possibilitar a problematização visando aferir os conhecimentos transmitidos em sala de aula, aliando teorização e contextualização.

\footnotetext{
${ }^{48}$ GIL, Antônio Carlos, Ibíd., p. 246., para aferir se os objetivos das Unidades do Programa de Ensino foram atingidas, bem como se a prova possui ou não deficiências e em que aspectos a experiência poderá produzir para o aprimoramento de outras avaliações no futuro.

${ }^{49}$ Neste diapasão, GIL, Antônio Carlos, Ibíd., pp. 249-250, destaca que a avaliação deve abranger os diferentes domínios de aprendizagem, bem como que as provas devem ser múltiplas e diversificadas: "O sistema de avaliação adotado na maioria de nossas escolas superiores tem privilegiado o domínio cognitivo, mais especificamente a memorização. A aprovação em muitas disciplinas e mesmo a conclusão de cursos, e, por extensão, em alguns concursos públicos, tem decorrido frequentemente muito mais da capacidade de memorização do que da compreensão dos conteúdos. O processo de avaliação deve ser capaz não apenas de verificar o que o estudante foi capaz de memorizar, mas também o nível de compreender o significado desse material e de transferência do que foi aprendido em aula para outras situações. E, conforme os objetivos formulados, que permita constatar se o estudante é capaz de proceder a análises, sínteses e avaliações". [...] "Há professores que manifestam inequívoca preferência por determinado método de avaliação. Também há os que nunca destinaram tempo razoável para o exame desta questão. E muitos são os professores que utilizam um único exame durante o semestre para aferir o aprendizado de seus alunos. Não existem boas razões para usar um único tipo de avaliação. Os professores devem diversificar suas avaliações, tanto em função das diferenças nas preferências dos estudantes pelo tipo de avaliação quanto de seu ajustamento aos diferentes objetivos. Também não existem razões plausíveis para realizar uma única se-ção de avaliação durante o semestre. Testar uma única vez significa negar feedback tanto para o professor quanto para o aluno acerca de seu progresso no curso".

${ }^{50}$ GIL, Antônio Carlos, Ibíd., p. 250 enfatiza as avaliações devem ser elaboradas com razoável antecedência: "As provas não podem ser elaboradas no momento em que o professor entra na classe. Devem ser preparadas com razoável antecedência. De preferência, à medida que os conteúdos forem sendo transmitidos. Dessa forma, o professor acaba por elaborar uma prova intimamente vinculada aos conteúdos que foram transmitidos ao longo do ano ou do semestre. Mesmo quando propõe questões objetivas cujo uso é repetido, convém que o professor revise sistematicamente essas questões, substituindo-as por outras ou procedendo a alterações em sua forma".
} 
Percebe-se que a concepção da prova não segue o "modelo clássico", na forma de perguntas do tipo "o que é?" ou "Disserte sobre...". A prova privilegia a contextualização do conhecimento teórico numa situação específica, com base num artigo de jornal, por exemplo. É esta, portanto, a habilidade que ela visa avaliar. Em suma, não basta o aluno reproduzir os conteúdos vistos em sala de aula. Exige-se do aluno a capacidade de aplicá-los numa situação dada. O objetivo de privilegiar esta habilidade não é uma atitude arbitrária. Pelo contrário, colima familiarizar o estudante, já nos primeiros anos do Curso de Direito, com a realidade profissional que irá defrontar-se após a sua conclusão, quando terá que aliar a teoria aprendida no transcorrer do Curso aos casos concretos. Além disso, a disciplina deixa de ser um estudo "arqueológico" das Ciências Sociais e sua interação com o Direito, para tornar-se um pensamento vivo, na medida que reflete e faz refletir a realidade social contemporânea. Desta forma, como já mencionamos anteriormente, a prova é mais um momento do processo ensino-aprendizagem e não o seu final.

Para finalizar, adotamos a prática de registrar o nome dos estudantes cujas respostas merecerem destaque, em cada uma das perguntas, e as respostas melhor elaboradas são digitalizadas e disponibilizadas para os alunos ${ }^{51}$ para que eles realizem o cotejo com sua prova, viabilizando identificarem os aspectos de acertaram e/ou erraram ou até mesmo faltantes nas suas respostas. Desta forma, a formulação das respostas "certas" não parte do professor, mas dos próprios alunos, valorizando a sua capacidade de argumentação, de escrita e de raciocínio.

\section{Considerações finais}

Conforme nosso propósito, apresentamos algumas nossas experiências de metodologia de ensino e de avaliação na disciplina Sociologia do Direito e esperamos que tenhamos possibilitado uma contribuição para suprir uma lacuna no campo da Didática do Ensino Superior no âmbito dos Cursos de Direito no Brasil, bem como para possibilitar a troca de experiências entre os professores da disciplina e para trazer subsídios para o aperfeiçoamento didático e da capacitação dos professores, para superar a tradição de um ensino baseado no comentário de artigos de leis ou de códigos (o ensino dogmáticotecnicista) ${ }^{52}$.

\footnotetext{
51 Para viabilizar o compartilhamento das respostas digitalizadas, criamos um blog vide: http://pt.scribd.com/doc/93699381/Primeira-Avaliacao-2012-DIREITO-E-SOCIEDADE-Respostas-que-merecemdestaque?secret_password=2dmpskl15b5jrpvoy91i - consulta 15 de junho de 2015.

${ }^{52}$ As análises e as críticas apresentadas neste artigo convergem com as proposições de MIAILLE, Michell Ibíd., p. 62, para construção de novos saberes e novas práticas didáticas e metodológicas para o ensino do Direito: “[...] Para desenvolver um estudo científico do direito, temos de forçar três obstáculos tanto mais sólidos quanto mais `naturais' parecem: a aparente transparência do objeto de estudo, o idealismo tradicional da análise jurídica, a convicção, finalmente, de que uma ciência não adquire o seu estatuto senão isolando-se de todos os outros estudos. O reconhecimento destas dificuldades conduz-nos desde logo a afirmar que temos de construir o objeto do nosso estudo - e não deixarmo-nos impor a imagem que o sistema jurídico veicula consigo - , subverter totalmente a perspectiva idealista e fraccionada do saber que domina atualmente. Como facilmente se pode constatar, a revelação destes obstáculos, quer dizer, a denúncia dos erros que eles fazem pesar sobre a definição e o desenvolvimento de um pensamento científico, não reveste o carácter gratuito de uma simples 'crítica'
} 
As reflexões aqui representadas também visam estimular os atuais professores e os futuros professores dos Cursos de Direito a perceberem a importância e a necessidade da Didática e da Metodologia do Ensino Superior para sua atuação.

Pretendemos com nossas análises e nossa leitura crítica, incentivar os docentes a repensarem as suas práticas didáticas e, sobretudo, perceberem a possibilidade de novos caminhos para construção do processo ensino-aprendizagem nos cursos jurídicos, além daqueles que tradicionalmente vem sendo repetidos de geração em geração.

Para tanto, o artigo visa encorajar os professores, em face dos desafios da docência no mundo em que vivemos, a darem asas à sua criatividade e a autenticidade, para criarem novas práticas e posturas na sala de aula, rompendo os simulacros e as ortodoxias didáticas dos Cursos de Direito, em prol de uma formação plena de estudantes, ou seja, preparando-os para participar e enfrentar do mundo além da escola.

\section{Referências Bibliográficas}

ARANHA, Maria Lúcia de Arruda e MARTINS, Maria Helena Pires. Filosofando, 4. ed., Moderna, São Paulo, 2009, 479 p.

BOURDIEU, Pierre. Lições de Aula, $2^{\text {a }}$. ed., Ática, São Paulo, 2003, 63 p.

CASTRO, Cláudio de Moura. Crônicas de uma educação vacilante, Rocco, Rio de Janeiro, 2005, 315 p.

CHAUI, Marilena. Convite à Filosofia, 14a . ed., Ática, São Paulo, 2011, 440 p.

JUNQUEIRA, Eliane Botelho. A Sociologia Jurídica no Brasil: introdução ao debate atual, Lumen Juris, Rio de Janeiro, 1993, 205 p.

PAVIANI, Jayme e POZENATO, José C. A Universidade em debate, EDUCS, Caxias do Sul, 1980, $193 \mathrm{p}$.

FARIA, José Eduardo e CAMPILONGO, CELSO FERNANDES. A Sociologia Jurídica no Brasil, Sérgio Antônio Fabris ed., Porto Alegre, 1991, 61 p.

FILHO, Álvaro Melo. Metodologia do ensino jurídico, 3ª ed., Forense, Rio de Janeiro, 1984, 182 p.

GHIRALDELLI JR., Paulo. Didática e teorias educacionais, DP\&A, Rio de Janeiro, 2000. 100 p.

negativa: leva-nos positivamente a constituir de outra maneira a ciência do direito. A crítica radical desta 'ciência' abre-nos a via de novas hipóteses científicas". 
GIL, Antônio Carlos. Didática do ensino superior, Atlas, São Paulo, 2009, 283 p.

HAIDT, Regina Célia Cazaux. Curso de didática geral, 2. ed., São Paulo, Ática, 1995, 327 p.

HOFFMANN, Jussara. Avaliação: mito \& desafio - uma perspectiva construtivista, $12^{\mathrm{a}}$. ed., Educação \& Realidade, Porto Alegre, 1993, 128 p.

KENNEDY, Duncan. La enseñanza del derecho: como forma de acción política, Siglo Veintiuno, Buenos Aires, 2012, 110 p.

LANCASTER, Lynne C. e STILLMANN, David. O Y da questão: como a geração Y está transformando o mercado de trabalho, Saraiva, São Paulo, 2011, 264 p.

LIMA, Abili Lázaro Castro de. A função e a importância das disciplinas propedêuticas na estrutura curricular dos Cursos de Direito no Brasil", Revista da Faculdade de Direito da UFPR, nº 42, Curitiba, 2006, p. 73-86.

. O discurso jurídico no contexto dos Cursos de Direito no Brasil: reflexões a partir das teorizações de Pierre Bourdieu, "in” FONSECA, Ricardo Marcelo (org.). Direito e discurso: discursos do direito. ed. Fundação Boiteux, Florianópolis, p. 105-122.

LÔBO, Paulo Luiz Neto. O novo conteúdo mínimo dos cursos jurídico. In: OAB ENSINO JURÍDICO: Novas Diretrizes Curriculares, Conselho Federal da OAB, Brasília, 1996, p. 10-11.

MACHADO, Antônio Alberto. Ensino jurídico e mudança social, 2a . ed., Atlas, São Paulo, 2009, p. $187 \mathrm{p}$.

MIAILLE, Michel. Introdução crítica ao direito, 2ª ed., Lisboa, Editorial Estampa, 1999, 328 p.

MALIANDI, Ricardo. Dejar la posmodernidad: la ética frente al irracionalismo actual, Editorial Almagesto,Buenos Aires, 1993, 321 p.

MORIN, Edgar. A cabeça bem-feita: repensar a reforma, reformar o pensamento, Bertrand Brasil, Rio de Janeiro, 2004, 128 p.

. Os sete saberes necessários à educação do futuro, Cortez, São Paulo, Cortez, 2000, 118 p. 